\title{
A Moderna Agricultura no final do século XIX em São Paulo: algumas propostas
}

\section{Modern Agriculture in Sao Paulo in the late $19^{\text {th }}$ century: some proposals}

\section{Amilson Barbosa HENRIQUES*}

Resumo: Esta pesquisa se insere dentro da história da agricultura no Brasil, especialmente no Estado de São Paulo, a partir da segunda metade do século XIX, início do século XX. As propostas de modernização agrícola giravam em torno de diferentes assuntos, mas sempre interligados, como: diversificação da agricultura, adubação química e natural, cultura intensiva do solo, mão de obra, povoamento e colonização, instalação de núcleos coloniais dentro dos moldes da moderna agricultura então desejada, instrução agrícola por meio de campos de experiências e demonstração, ensino agrícola para diferentes graus, a mecanização da lavoura, o que era chamado, na época, de Moderna Agricultura, em substituição ao que era considerado como agricultura rotineira ou atrasada, praticada desde o início da agricultura no Brasil.

Palavras-chave: Moderna Agricultura. Estado de São Paulo. Cafeicultura.

Abstract: This study immerses itself in the history of agriculture in Brazil, especially in the State of São Paulo, from around the late 19th century and beginning of the 20th century onward. The agricultural modification proposals revolved around different subjects, but always interconnected, such as: agricultural diversification; natural or chemical fertilization; intensive soil culture; labour, population and colonization; installation of colonial areas attending the desired patterns and necessities of modern agriculture; farming instruction through experience and demonstration in the fields; farming education at different levels; farming mechanization, which was called Modern Agriculture by that time; in substitution for what had been considered to be routine and outdated agriculture, practiced since the beginning of agriculture in Brazil.

\footnotetext{
* Mestre em História - Doutorando - Programa de Pós-Graduação em História - Faculdade de Ciências e Letras de Assis - UNESP - Univ. Estadual Paulista, Campus de Assis - Av. Dom Antônio, 2100, CEP: 19806-900, Assis, São Paulo Brasil. E-mail: amilson_barbosahenriques@yahoo.com.br
} 
Keywords: Modern Agriculture. State of São Paulo. Coffee growing.

\section{Introdução}

A modernização da agricultura foi, em diversos casos, pensada no Brasil como um fenômeno de meados do século XX em diante, relacionada com o que se convencionou chamar de revolução verde (GRAZIANO NETO, 1982). Contudo, algumas pesquisas destacam que propostas e tentativas de modernização da agricultura brasileira foram feitas ao longo do século XIX, sobretudo depois da segunda metade (HENRIQUES, 2010) ${ }^{1}$. Este artigo propõe analisar alguns autores, agrônomos e estudiosos na temática agrícola em uma publicação especializada, a Revista Agrícola paulista. ${ }^{2}$

Vale ressaltar que o periódico analisado está profundamente relacionado com a sociedade na qual foi gerado, marcado pela grande produção cafeeira, a incipiente mão de obra assalariada e livre, bem como o contexto de superprodução da rubiácea e a crise econômica advinda. Neste sentido, a leitura desse periódico permite, ao mesmo tempo, proceder a uma descrição deste meio social, que emerge das entrelinhas dos textos, e ressaltar as críticas e concepções dos autores a respeito dela, além, é claro, das proposições para a mudança da agricultura praticada (LUCA, 2005).

O objetivo deste trabalho é acentuar algumas propostas de modernização da agricultura com base em alguns autores selecionados, e que foram discutidas, ensaiadas, experimentadas e analisadas por dezenas de agrônomos, fazendeiros e políticos no final do século XIX e adentrando o século XX, em São Paulo, sendo relatadas principalmente na Revista Agrícola. Os artigos, bem como o periódico, são analisados pelo ponto de vista de uma história política e da ciência, ou seja, procura-se penetrar nas relações sociais que este veículo pressupõe e as relações que este mantém com a realidade histórica em que foi produzido e para a qual foi dirigido (MARTINS, 2001). Além disso, existe a preocupação com a história ambiental, a relação dos fazendeiros e agricultores para com o meio ambiente e do meio ambiente interagindo com o homem. (WORSTER, 2003).

\section{São Paulo no final do século XIX: a modernidade bate à porta}

O século XIX é conhecido como “a era da ciência”. Aquele final de século representou o momento do triunfo da modernidade que era ambicionada por boa parte da população brasileira naquele período. Símbolos da modernidade, a velocidade e a rapidez eram os lemas daquele momento, no qual o eixo Rio de Janeiro - São Paulo era o mais expressivo da cultura e da vida material da virada do século XIX para o XX, sendo polos centralizadores e difusores de modas e costumes europeus e norte-americanos. Para se ter uma ideia, na passagem do século, o Rio de 
A Moderna Agricultura no final do século XIX em São Paulo:

algumas propostas.

Janeiro era o $15^{\circ}$ porto do mundo em volume de comércio, superado na América apenas por Nova Yorque e Buenos Aires. São Paulo registrava, em 1903-1904, um total de cerca de 1.200 navios de diversas nacionalidades desembarcando e embarcando mercadorias em seu litoral (SÃO PAULO, 1905, p. 165).

Aquele era um momento, portanto, em que certa "burguesia agrícola e industrial”, confiante no seu avanço e riquezas, viu na ciência a possibilidade de expressão de suas mais altas ambições. Tal qual uma revolução industrial sem fim, aqueles homens passaram a tentar domar a natureza valendo-se de uma miríade de invenções. Cada novo invento levava a uma cadeia de inovações que, por sua vez, abria perspectivas e projeções inéditas. Dos inventos fundamentais e importantes aos mais surpreendentes e inutilizados, das grandes estruturas aos pequenos detalhes, uma cartografia de novidades cobria os olhos daqueles homens, estupefatos com suas máquinas maravilhosas (COSTA; SCHWARCZ, 2000).

As exposições universais passavam a demonstrar didaticamente o progresso e imaginar o futuro. As feiras e exposições nacionais e internacionais atingiram uma média de mais de 200 encontros anuais, por volta de 1910-1913, e o Brasil esteve representado em muitas delas, graças à iniciativa do governo imperial, e, mais tarde, de seu sucessor republicano (LOVE, 1982, p. 303304). Assim, como ressalta Almir P. Freitas Filho (1991, p. 73) as exposições divulgavam “os resultados do labor técnico e das conquistas científicas dos homens em relação ao domínio da natureza”. Para este autor, as exposições, além de funcionarem como uma amostragem muitas vezes parcial e incompleta do estágio econômico, técnico e cultural do país, também apontavam para suas carências, indicando, desse modo, formas mais concretas de intervenção na realidade.

Imaginou-se e sonhou-se muito na passagem do século XIX para o XX. Era esse o momento das realizações, da efetivação de projetos de controle das intempéries naturais. Essa verdadeira “ideologia do progresso” e os novos avanços técnicos traziam a confiança de um domínio absoluto sobre a natureza e os homens (SEVCENKO, 2003).

As ambiguidades do progresso, porém, também estavam presentes, de forma marcante. A mesma luz elétrica que movia os bondes e começava a tirar as cidades da escuridão da iluminação a lamparinas, lampiões a vela e a óleo, promoviam acidentes e colisões muitas vezes fatais. Os novos carros que começavam a circular causavam engarrafamentos e trombadas nas ruas estreitas, sobretudo quando emparelhados aos veículos de tração animal. Por fim, não há como esquecer que a escravidão havia deixado marcas evidentes no cotidiano da população (SEVCENKO, 2003).

Seria muito difícil esquecer ou apagar em poucos anos o fato de ter sido o Brasil a última nação a abolir oficialmente a escravidão na América, já que até maio de 1888 era possível garantir a 
compra de uma pessoa para ser suas mãos em diversos trabalhos diários. Era difícil a convivência entre o "projeto republicano" que, inaugurado em novembro de 1889, divulgava uma imagem de modernidade e, a lembrança recente do sistema escravocrata, que levava à conformação de uma sociedade patriarcal, marcada pelas relações de ordem pessoal e violenta, na qual vigorava absolutamente um profundo preconceito em relação ao trabalho braçal (DEAN, 1977).

Em meio a esse ambiente, porém, civilização e modernidade convertiam-se em palavras de ordem, viraram instrumentos de luta e discussão, além de imagens de um ideal desejado. O Brasil entrava no século XX tão confiante nesse ideal como as demais nações do mundo: nada como imaginar que seria possível domesticar o futuro, prever e impedir flutuações financeiras, domar a natureza aos desígnios humanos. Sem dúvida, esse é o tempo que aposto em verdades absolutas, pois científicas, em normas morais rígidas, na solução de todos os problemas imponderáveis, fiouse em modelos que distinguiam, de forma insofismável, o certo do errado (SEVCENKO, 2003). Não é à toa que tenha sido considerado por um historiador como um século longo. Como afirmou Eric J. Hobsbawm, para além das datas que estancam os marcos (história factual), o século XIX teria terminado apenas no ano de 1914. Foi, então, e com a realidade da Primeira Guerra Mundial, que se pôs fim a esse “tempo das certezas” (HOBSBAWM, 1995) ${ }^{3}$.

No começo do século XX acreditava-se, sobretudo, nos confortáveis valores de um contexto em que certas verdades religiosas e a lealdade à pátria estavam na ordem do dia. O mundo estava menor diante do desenvolvimento dos transportes de massa, como ferrovias e navios a vapor. Não é à toa que os grandes símbolos daquele momento fossem a luz e a velocidade.

Neste contexto, o caráter global da economia capitalista consolida-se no século XIX, atingindo fronteiras intocadas e descortinando barreiras geográficas, políticas, sociais e econômicas. A raiz dessa dinâmica expansionista pode ser vinculada à Revolução Industrial de meados do século. Esse verdadeiro surto da economia industrializada se baseou em três elementos básicos: o ferro, o carvão, e as máquinas a vapor. No entanto, é o momento seguinte que mais nos interessa. Trata-se de pensar nas decorrências da Segunda Revolução Industrial - também conhecida como Científico/Tecnológica -, ocorrida, sobretudo, depois da década de 1870. Essa revolução levou à aplicação das recentes descobertas científicas aos processos produtivos da economia, possibilitando o desenvolvimento de novas fontes de potenciais energéticos, como a eletricidade e os derivados do petróleo, assim como a hidráulica e o carvão, que geraram mudanças de impacto nos mais diferentes setores: na indústria, biologia, microbiologia, química aplicada, farmacologia, medicina, na higiene e profilaxia, engenharia entre outros (HOBSBAWM, 1995). E na agricultura, o que foi pensado e feito? 
A Moderna Agricultura no final do século XIX em São Paulo:

algumas propostas.

Foi em meio a esse processo que apareceram os veículos automotores, os transatlânticos, os aviões, o telégrafo, o telefone, a iluminação elétrica, uma extensa variedade de utensílios domésticos, a fotografia, o cinema, a radiodifusão, a televisão, construções grandiosas da engenharia e seus elevadores, as escadas rolantes e os sistemas metroviários, os parques de diversões elétricos, as rodas-gigantes e as montanhas-russas, a anestesia, a penicilina, o estetoscópio, o medidor de pressão arterial, a dinamite, os processos de pasteurização e esterilização, os adubos artificiais, o papel higiênico, a escova e a pasta de dentes, o sabão em pó, os refrigerantes com gás, o fogão a gás, as comidas enlatadas, as cervejas engarrafadas, a aspirina, e antiácidos. Era o chamado “mundo moderno" que surgia na frente dos olhos das pessoas (HOBSBAWM, 1995).

No entanto, o progresso histórico dentro do capitalismo é bastante ambíguo. Essa verdadeira escalada na produção dos países ocidentais, fundamentalmente, levou, por sua vez, à disputa por matérias-primas disponíveis no mundo, bem como, à ampliação do mercado e ao fenômeno conhecido como neocolonialismo ou imperialismo. Fenômeno esse que acarretou uma nova divisão internacional de áreas não colonizadas - ou, ainda, promoveu novas relações de dependência em áreas de passado colonial. A maior potência econômica da época, a Inglaterra, em 1900, incluía em seus domínios possessões em todos os continentes, que ao todo chegavam a ter mais de 28 milhões de quilômetros quadrados, ou quase um quinto de toda a superfície do planeta terra e cerca de 400 milhões de pessoas ou um quarto da população total do mundo naquele momento. De certo, a Inglaterra possuía o domínio militar e econômico do mundo naquela época. Mesmo assim, começava a entrar em cena um país bem mais jovem: os Estados Unidos da América. (HOBSBAWM, 1975).

A despeito da sua feição de triunfo e progresso, a belle époque tinha várias faces, entre as quais estão a pobreza e a miséria em franca expansão, ao lado da grande concentração de riqueza disposta a poucos elementos da massa da população (SEVCENKO, 2003).

De qualquer maneira, de forma mais ou menos direta é possível perceber o ideário de uma época que, volta e meia, colocava em evidência as conquistas científicas alcançadas pelo homem, bem como seus efeitos contrários. Mesmo com tantas certezas, há sempre a apreensão diante do que não se pode planejar com certo grau de precisão. Utopias trazem certezas e, também, muitas dúvidas. O mundo que se debruçou sobre o século XX mostrou sua face mais idílica e otimista, mas não conseguiu esquecer o temor do porvir. Ainda assim, modernidade combina com avanço e - nesse caso - progresso. Era essa a face brilhante do teatro da modernidade que o Brasil queria acompanhar, já que não era possível tomar a dianteira. (COSTA; SCHWARCZ, 2000, p. 25). 
Foi neste contexto que diversos intelectuais, grandes fazendeiros do chamado Oeste Paulista, agrônomos formados em famosas escolas agrícolas da Europa, como Grignon e Montpellier na França, Hohenheim na Alemanha e o Institut Agrícola de L'État de Gembloux, na Bélgica, advogados, políticos e outros, queriam trazer para a agricultura paulista o que de mais moderno era feito e usado em países do Velho continente e nos Estados Unidos, no intuito de modificar sua feição, sua característica. Queriam produzir muito e barato, produzir diversos produtos, com reduzida, porém qualificada mão de obra, e com sabedoria científica, por isso, o seu “nome”: agricultura científica, racional, moderna, nas palavras daquelas pessoas. Mas as propostas de modernização agrícola não foram acompanhadas de poucos debates e contradições.

A partir da década de 1870, São Paulo tornava-se um lugar privilegiado das transformações socioeconômicas, urbanísticas, físicas e demográficas. Bem no meio da prosperidade crescente da lavoura cafeeira e das tensões ligadas à crise final da escravidão no país, a cidade se transformava de forma acelerada na "metrópole do café”. Todo esse conjunto de fatores implicou, por sua vez, em alterações profundas nas funções e espaços da cidade, em favor de um maior controle e racionalização, de modo a assegurar para São Paulo o importante status de entreposto comercial e financeiro privilegiado para as relações entre a lavoura cafeeira paulista e o capital internacional (LEMOS, 1989).

São Paulo também acompanhou as diversas reformas progressistas do momento, como por exemplo, a reforma urbanística que começa em 1872, com o governo de João Theodoro Xavier de Mattos, para poder receber os grandes proprietários e capitalistas da então mais próspera província do Brasil. E foi isso mesmo que aconteceu, ancorado na necessidade de ampliação da comunicação de transporte com o interior para o escoamento da produção de café e o deslocamento de pessoas. Segundo Odilon Matos, em 1870 a Província de São Paulo possuía 830 mil habitantes, 60 milhões e 462 mil pés de café e 139 quilômetros de ferrovias. Já em 1900, o Estado de São Paulo suportava 2 milhões e 279 mil habitantes, mais de 220 milhões de pés de café, e 3.373 quilômetros de ferrovias (MATOS, 1990). Não era pouco.

Neste sentido, o que interessa enfatizar é: Quais foram as propostas de modificação ou modernização da agricultura no período? Apresentar-se-á, aqui, algumas delas. 
A Moderna Agricultura no final do século XIX em São Paulo:

algumas propostas.

\section{A Moderna Agricultura e a crítica à Agricultura Tradicional}

A virada do século (XIX-XX) foi cenário de discussão bastante acirrada sobre a técnica agrícola entre os cafeicultores e lavradores. Não se sabia ao certo se seria proveitoso introduzir a mecanização no cultivo. Ou seja, em lugar da considerada “primitiva enxada”, valeria à pena utilizar as novas máquinas de tração animal, os instrumentos aratórios? Aqueles que eram favoráveis alegavam que cada arado valia por mais de uma dezena de trabalhadores (ou colonos), e tinha por vantagem não remeter dinheiro para o estrangeiro e nem sangrar o Tesouro nacional com despesas de transporte com a imigração, e também não reclamavam e nem geravam conflitos e discussões, às vezes com término violento no interior dos estabelecimentos rurais (STOLKE, 1986). ${ }^{4}$

Costumava-se dizer, por outro lado, que a redução de trabalhadores na lavoura causaria problemas na hora da colheita, o que era contestado por alguns entusiastas que eram a favor da mecanização agrícola. Na opinião dos mais céticos ou realistas, com a máquina poderia haver descontrole das lâminas do arado, ou que os aparelhos não eram apropriados à cultura do cafeeiro, pondo em risco, por isso, o corte, prejudicando as raízes da planta, além de não se chegar às áreas montanhosas - essa última, uma crítica clássica no Brasil para não fazer uso de instrumentos aratórios (HOLANDA, 1995, p. 66-70).

Por sua vez, os trabalhadores ou imigrantes temiam as inovações, já que não poderiam plantar seu milho e feijão nas ruas dos cafezais, devido às máquinas, e o desemprego seria certo, fato esse também contestado por diversos entusiastas, que consideravam que o fazendeiro poderia deixar o trabalhador cultivar seus alimentos em uma área especialmente dedicada a isso, ou que estes fossem estabelecidos em núcleos coloniais (particulares ou do Estado), onde na época das colheitas eles seriam chamados ao trabalho nas grandes propriedades novamente (eram chamados estes núcleos por isso de “viveiros de trabalhadores” por alguns especialistas).

As outras operações agrícolas (excluindo aqui a colheita) seriam feitas com pouco uso de mão de obra, visto que o uso dos instrumentos aratórios e modernos economizariam grande parte da força de trabalho empregada até então. Devido a isso, os trabalhadores poderiam tocar seus pequenos estabelecimentos rurais (lotes) a seu bel prazer e, que também seria condicionada ao trabalho dos “aparelhos aperfeiçoados”, instrumentos aratórios em geral, que facilitaria o trabalho diário (pois era puxado por animais de tração) economizando tempo e trabalho físico, aumentando a produção e sua qualidade, economizando espaço e tratando (lidando ou poupando) o solo como nunca se havia feito antes (HENRIQUES, 2010). 
É neste contexto que surge uma das primeiras publicações sobre agricultura em São Paulo, no período republicano: a Revista Agrícola. Órgão da Sociedade Pastoril e Agrícola. ${ }^{5}$. A Sociedade Agrícola e Pastoril surgiu em março de 1895, na capital do Estado, na Rua Líbero Badaró, n. 117, sediada em um dos salões do Club da Caça e Pesca por iniciativa de Domingos J. N. Jaguaribe (1848-1926) seu fundador, político e fazendeiro, ativo propagandista da modernização da agricultura e, também por iniciativa de grandes fazendeiros residentes em São Paulo, como Carlos José de Arruda Botelho (1855-1947), filho primogênito de Antônio Carlos de Arruda Botelho (1827-1901), conde do Pinhal, Bernardo Avelino Gavião Peixoto (1829-1912) e Luiz Vicente de Souza Queiroz (1849-1898) (REVISTA AGRÍCOLA, 1895, n. 1 ano I, 1895. p. 1-5).

Entre os temas que veicularam nas páginas deste periódico (alguns deles muito bem estudados pela bibliografia especializada), estavam os mais candentes da época, quais sejam: os impasses da imigração; a difícil implantação de núcleos coloniais pelo governo e por particulares; o êxodo dos colonos das áreas e fazendas produtoras; a necessidade sempre presente de diversificação da agricultura e suas consequências na economia e na vida da população em geral; o fracionamento da grande propriedade e as dificuldades com relação à mecanização da lavoura em substituição à agricultura que consideravam como atrasada, rotineira e tradicional.

No reboque de tais propostas esteve presente, por diversas vezes - mais em uns autores, menos em outros -, o destaque da agricultura intensiva, a agricultura considerada racional, que na visão de alguns deles significaria mais alimento à população, o mais barato possível, bem como a fixação do colono à terra em pequenas propriedades, a conservação da floresta e do seu solo para que as futuras gerações (era essa a expressão usada por diversos autores) pudessem usufruir de um patrimônio que já era olhado como um recurso e que poderia um dia acabar. ${ }^{6}$

No retorno dos estudos na Europa, como de praxe na época, os jovens herdeiros de vastos patrimônios materiais, formados em direito, engenharia, medicina e também em agronomia não possuíam apenas visões políticas e ideológicas diferentes das dos seus pais e avôs em relação ao escravismo, ao Império, mas, sobretudo, desejavam ver a modificação da agricultura considerada tão atrasada que nem o nome de agricultura deveria ter àquelas práticas agrícolas aqui vislumbradas. Ao que parece, este ambiente de mudanças radicais, na política, sociedade, cultura, intelectualidade, etc., foi um movimento bem amplo na sociedade do período do final do século XIX e início do século XX (SALLES, 1986) ${ }^{7}$.

Neste sentido, na crítica à agricultura considerada atrasada e irracional é que surgem na Revista Agrícola as propostas de sua modificação. As críticas de diversos autores, observações e opiniões recaíam na chamada Agricultura Tradicional (irracional, rotineira e atrasada eram os termos utilizados para caracterizar essas práticas agrícolas), praticada desde os tempos coloniais, de 
A Moderna Agricultura no final do século XIX em São Paulo:

algumas propostas.

técnicas e instrumentos simples (a foice, o machado, a enxada e o tição são os seus símbolos principais), baseava-se na derrubada e queimada de florestas virgens e de solos férteis, a fim de abrirem-se novos campos de cultivo, o plantio era desordenado e o solo era utilizado sem nenhuma forma de correção e adubação. Esse modelo de exploração do solo induzia a uma espécie de “nomadismo agrícola”, pois o campo aberto pela queimada, a princípio muito fértil, desgastava-se rapidamente por outras queimadas, e pela falta de cuidados, em cerca de 20 a 30 anos a terra era inutilizada para a agricultura. Seguia-se, então, uma nova derrubada e queimada de matas para a exploração agrícola expandindo a área cultivada, deixando para trás campos desgastados (DEAN, 1996) $)^{8}$.

Para aqueles autores, com a substituição da agricultura praticada, o país poderia alçar economicamente ao patamar dos países mais industrializados e progressistas do mundo, como a França, a Inglaterra e os Estados Unidos. A moderna agricultura que resumidamente pode ser caracterizada pelo uso de princípios e pesquisas científicas e tecnologias na organização do trabalho agrícola, tais como: a diversificação da agricultura (policultura); a implantação de colônias para fixar o colono a terra, servindo este como trabalhador eventual na grande lavoura de exportação, produzindo ainda alimentos ao mercado interno e externo, tornando-os pequenos proprietários; a pesquisa agrícola para a produção ou adaptação de novos conhecimentos, e o ensino agrícola, bem como, a intensificação agrícola no cultivo do solo; o uso de defensivos e adubos (químicos e orgânicos) em conjunto com a mecanização da lavoura; o advento de campos de experiências e demonstração de culturas onde os agricultores poderiam ser instruídos e vislumbrar as práticas e instrumentos agrícolas modernos em ação; a divulgação de diferentes culturas agrícolas e os seus resultados para que servisse de modelo a ser imitado, vislumbrando-se a possibilidade da implantação da policultura para abastecimento do mercado interno e também externo.

\section{Algumas propostas de modernização da agricultura em São Paulo}

Vejamos, então, algumas propostas relativas aos métodos de cultivo do solo, o emprego de adubos químicos e a conservação das florestas e de seu solo, contidas na Revista Agrícola paulista.

Na Revista Agrícola de novembro de 1895, Guilherme Schüch Capanema (1824-1908) ${ }^{9}$ escreveu sobre as Queimadas (FIGUEIRÔA, 2005). Advertia o autor que as florestas na América sempre foram "rapinadas” pelos homens, mas que, com o advento das lavouras de exportação e a multiplicação dos lavradores durante os séculos, a cultura do solo tornava-se cada vez mais predatória. Destacava, ainda, que com o desenvolvimento das ciências, os homens iriam ser forçados necessariamente a fazer um aproveitamento mais racional do solo cultivado. Encantado 
pela época em que vivia, de descobertas e inovações em diversas áreas do conhecimento, salientou Capanema:

[...] os homens deixaram de ser escravos cegos das idéias seculares, principiaram a compreender as leis da natureza, investigá-las e aplicá-las, acumularam com paciência e aturado trabalho, matéria para os assombrosos recursos de que hoje dispomos, cuja simplicidade admiramos, porém que para seu desenvolvimento careceram mais de um século: assim o vapor e a eletricidade (CAPANEMA, 1895, p. 91).

Devido ao progressivo desenvolvimento humano nas ciências diversas, nos materiais, na química e na biologia, por tudo isso, Capanema tinha a esperança de que "um dos resultados mais modestos, é sem contestação o mais importante, pois que nos garante os meios de viver, que os nossos antepassados tendiam a destruir”. Referia-se à agricultura, “que entre nós ainda é um sistema de rapina, nós nos apoderamos do que a natureza nos oferece, mas não nos lembramos de lhe pagar aquilo de que tiramos proveito, e que esgotamos os depósitos que deveríamos manter sempre bem sortidos” (CAPANEMA, 1895, p. 91).

Em seu artigo, Capanema demonstrou que, apesar de viver um momento ímpar dentro da história mundial, um momento de progresso e de descobertas científicas, entretanto, a despeito disso os homens no Brasil não se davam conta do valor quando encontravam uma bela floresta com frutos alimentícios, preciosas substâncias medicinais, e matérias-primas para a indústria, e que constam de água, ácido carbônico, azoto, sais de potássio, cálcio e magnésio, acido fosfórico-sulfúrico, etc. elementos importantes ao corpo humano e na agricultura -, acumulados lentamente nestas árvores durante muitas dezenas de anos e mesmo séculos (CAPANEMA, 1895).

O que queria dizer é que o agricultor não se aproveitava de todo o potencial que a natureza oferecia ao homem. Não se sabia ainda aproveitar aquilo tudo. Ao contrário: "Derrubamos as matas e lhe atacamos fogo, a água, o ácido carbônico e o azoto lá se vão pelos ares, ficam nas cinzas os sais alcalinos solúveis na água, e sais de terra alcalinas pouco, os insolúveis.” Princípios químicos e orgânicos tão caros ao aproveitamento da agricultura (CAPANEMA, 1895, p. 91).

Desta maneira, sobre o uso histórico da queimada na agricultura para abertura de campos ao cultivo do solo, Capanema ressaltava que, se após a queimada das florestas ou capoeiras não viesse uma chuva fina, “criadeira”, como a chamavam os lavradores, os sais solúveis penetravam no solo, onde eram, na maior parte, retidos pela terra. Porém, se caísse uma chuva torrencial estes princípios essenciais seriam levados pela enxurrada, e não enriqueceriam o terreno para produção de "vegetais vorazes", como os cereais que "são os veículos em que pelo seu consumo adquirimos o fosfato de cal para formação dos ossos do nosso corpo e sais que entram na composição da nossa carne, etc.” 
A Moderna Agricultura no final do século XIX em São Paulo:

algumas propostas.

(CAPANEMA, 1895, p. 91). Porém, isto só não bastava; “precisamos ainda do azoto, que os vegetais nos proporciona em forma de albuminas, proteínas, etc.” (CAPANEMA, 1895, p. 91). Para ele, algumas plantas tinham a propriedade de absorver o azoto (nitrogênio) do ar, a maior parte, porém, o recebiam do solo onde as raízes o encontravam em forma de nitratos, "transformação lenta das folhas, lenho e raízes”. Mas, "pelas queimas destruímos imensa quantidade de fontes de azoto em condições de ser assimilado.” (CAPANEMA, 1895, p. 91).

Capanema advertia, também, que não era apenas dos vegetais que os homens retiravam os alimentos necessários ao corpo humano, sua nutrição geral. Os homens recorriam também à alimentação com carne de outros animais que vivem de pastos. Segundo o autor, os pastos cobriam vastas extensões de terreno, mas que não eram perenes, pois, a maior parte de sua vegetação era anual, excluindo o que não era consumido seco (forragens).

Então entendeu o selvagem (alusão a coivara praticada pelos índios) que devia queimar o capim seco afim de nascer com maior vigor a planta nova. Há nisso uma boa razão de ser: libertam-se os sais nutritivos contidos nessa erva em condições insolares na maior parte, e espalham-se em formas solúveis sobre o solo, onde parte penetra, e muita é levada pelas enxurradas, indo alimentar plantas aquáticas em rios, lagos e mares distantes. (CAPANEMA, 1895, p. 91).

Apesar disso, Capanema constatou que "A conseqüência destas queimadas repetidas é empobrecimento, esterilização do terreno do que por toda a parte encontramos provas." (CAPANEMA, 1895, p. 91). Por tudo isso, saltou aos seus olhos quando fez uma viagem ao Paraná, nos “afamados Campos Gerais”:

[...] onde se dizia abundar o celebrado capim mimoso; tive curiosidade de vê-lo, mas só existia ainda em raros vales, tendo a maior parte desaparecido, não só pela esterilização, mas porque vai formando moitas não tem serapilheira ${ }^{10}$ de raízes, cuja camada, como acontece ao barba de bode que substitui, formando densas touceiras e pouco prestando para o pasto.

Nesses lugares não vi samambaia ${ }^{11}$, que anos depois encontrei estendendo-se com rapidez. (CAPANEMA, 1895, p. 91).

Em contraposição ao que era praticado no Brasil, sem fiscalização e tão pouco leis para infringir as queimadas e a mudança de hábitos considerados como nocivos, Capanema destacou que havia recebido de uma biblioteca em Curitiba um livro sobre os Estados Unidos, "país de ampla liberdade, onde a pessoa do cidadão é inviolável, senhor inteiramente de seus atos”. E depois de ler o livro com atenção, constatou “que apesar dessas garantias, havia proprietários de campos que não tinham a liberdade de dispor a seu talento de sua propriedade, havendo uma lei que os punia com 
pesada multa e cadeia quando se lembrasse de por fogo aos seus campos de criação nos vastos pampas (patries) americanos.” (CAPANEMA, 1895, p. 91).

O liberalismo norte-americano era então visto sob o bem comum, da sociedade, e não apenas dos particulares. E não era apenas isso. O exemplo norte-americano deveria ser imitado em diversos aspectos no Brasil, como destacou Capanema:

É que os americanos, que nos jactamos de imitar, têm, além de muitas qualidades que nos faltam, muito bom senso, entenderam que deviam criar a cada canto comissões permanentes exclusivamente incumbidas de estudar borboletas, carrapatos, piolhos de plantas e dos bichos, caracóis, mofos, e quanta mais praga (que consome $25 \%$ da produção agrícola do trabalho do homem, tributo que o mais despótico governo não se anima a impor.) além disso estudam composição de terrenos, suas alterações, melhoramentos, etc. (CAPANEMA, 1895, p. 91-92).

Conforme havia lido, essas comissões científicas americanas verificaram que as queimas dos campos empobreciam o solo em proporções cada vez maiores e propuseram que, por lei, se multasse o cidadão que quisesse, voluntariamente, sacrificar seus recursos, e, além disso, o fizesse refletir sobre seu ato na cadeia. Era a ciência a serviço da agricultura que pedia o autor, e leis que valorizassem os recursos naturais, e instruíssem os homens a praticarem uma agricultura mais racional, utilizando os Estados Unidos como o exemplo a ser imitado (mas não transplantado).

Seguiu o autor dissertando a respeito dos experimentos de cientistas europeus sobre a composição química do solo, bem como sobre adubos químicos e naturais que seriam necessários a reposição dos seus nutrientes. No artigo, Capanema (1895) destacou que havia feito, ele próprio, embasado nos experimentos do diretor do Instituto Agronômico de Campinas, Franz Josef Wilhelm Dafert (1887-1897) experiências com adubação. Apesar dos testes e experimentos de Capanema, ao que parece, terem sido por algumas vezes de resultado frustrante, chegou a um bom resultado e combinação de adubos para utilização nas terras, e para os lavradores fazerem uso ou se apoiarem.

Segundo ele, depois de demonstrar as experiências dos autores aludidos (europeus e de Dafert no Instituto Agronômico) que provaram o quanto seriam nocivas as queimadas aos solos e seus nutrientes, o quanto era perdido devido a esse procedimento, o autor salientou que era preciso “sobretudo entre nós (homens de ciência preocupados com agricultura) procurar em um meio de habilitar, sobretudo o pequeno lavrador e seus camaradas que muitas vezes nem ler sabem, a empregar com acerto os ingredientes nutritivos na terra” (CAPANEMA, 1895, p. 92). A seu ver, os agricultores e trabalhadores não tinham conhecimento suficiente sobre os produtos químicos para a adubação do solo, pois, “custa entrar-lhes na cabeça (dos lavradores) a compreensão do fosfato ${ }^{12}$ e 
A Moderna Agricultura no final do século XIX em São Paulo:

algumas propostas.

superfosfato de cal $^{13}$ ou de potássio, nitrato ${ }^{14}$, sulfato $^{15}$ disto ou daquilo, e quando decorem os nomes, não se evitam as trocas” (CAPANEMA, 1895, p. 92).

Até mesmo com o próprio Capanema esse erro havia sido cometido, atestando que a utilização, e antes disso, as experiências com adubos químicos em São Paulo eram incipientes, pois um intelectual como Capanema ainda não estava familiarizado com os insumos de que dispunha para a realização dos seus intuitos científicos e agrícolas, pois, segundo ele no artigo:

Desta fui vítima (confusão com os compostos químicos para adubação), evitei-o de modo a poder confiar a composição de adubos ao mais ignorante trabalhador; eu tinha cada um dos sais em barris com cores diferentes, e as minhas receitas eram: "tantas canecas do barril vermelho, tantas do verde e untada com tantas quartas de terra.”. Isto nada tinha de aristocraticamente científico: era, porém, muito democraticamente prático.

Cheguei mesmo a formular a receita com riscos de diversas cores cada um representando uma caneca do respectivo ingrediente. (CAPANEMA, 1895, p. 93, ênfase do original).

Eram estes os passos que Capanema havia seguido e que deu publicidade na Revista para que o agricultor também pudesse utilizar como resultado de seus experimentos:

1. Enterre cisco de capina ${ }^{16}$, resíduos de toda espécie, e manipule;

2. Prepare diversos caixões contendo terra com esse cisco, e em cada um adicione alguma fórmula dos ingredientes (dos adubos químicos).

3. Quando pronto, plante nessas diversas caixas uma muda do vegetal que quer cultivar;

4. Coloque os caixões juntos, regue-os todos ao mesmo tempo e com a mesma quantidade de água;

5. Acompanhe o crescimento de suas plantas, observe qual a formula (até marcada nos caixões com os riscos de cor) que dê o melhor resultado, e a aplique à sua plantação;

6. Não espalhe simplesmente o adubo na superfície do terreno sobretudo no inclinado, como muito aconselham. Vindo uma garoa demorada isto aproveita, mas chuva grossa leva todo estrume embora. (CAPANEMA, 1895, p. 93).

Não esquecendo que seria sempre conveniente misturar o adubo com a terra, ou fazer regos ou covas em torno da planta, lançando dentro destas, porções adequadas do adubo - "excesso é prejudicial - cobri-lo com terra.” E, no final do artigo, Capanema enfatizava que não haveria fórmulas prontas de adubos, mas que todos os detritos de uma propriedade rural deveriam ser aproveitados como adubos na lavoura, nada deveria ser descartado. “Assim cada um se guiará pela própria experiência.” (CAPANEMA, 1895, p. 93). 
A opinião básica contida neste artigo de Capanema era a opinião também de dezenas de outros autores que escreveram na Revista Agrícola em todo o período da publicação. As queimadas deveriam ser evitadas. O solo deveria ser mais bem aproveitado no tempo e espaço, aumentando a produtividade das culturas em sua qualidade e quantidade (produzir muito e barato era o lema daqueles intelectuais), com a utilização de adubos, fossem eles químicos ou naturais, ou a combinação dos dois, se servindo também dos instrumentos aratórios (mecânicos).

Naquela época, algumas pessoas estavam realizando experiências com o solo, principalmente dos cafezais. Os compostos mais analisados eram os fosfatos de cal, os superfosfatos, nitratos diversos, e outros produtos. A maioria dos produtos químicos que eram vislumbrados como adubo provinha do exterior e eram demasiadamente caros aos agricultores em geral, mas principalmente aos menores.

Luiz Vicente de Souza Queiroz (1849-1898) ${ }^{17}$ foi um dos defensores da utilização dos adubos químicos naquele momento, na agricultura. Segundo ele, em Ipanema, interior de São Paulo, havia uma reserva bastante grande de calcário que poderia servir para a exploração dos fosfatos necessários à adubação do solo paulista destinado à agricultura, senão para todo o Brasil. Em suas palavras:

\begin{abstract}
Realmente não há povo tão pouco prático e tão pródigo ${ }^{18}$ como o povo brasileiro; importamos milhares de toneladas de fosfato de cal, que é pago a razão de $300 \$ 000$ por tonelada pouco mais ou menos, quando a poucas horas desta cidade (São Paulo), em Ipanema, existem soberbas jazidas desta matéria fertilizante, que poderia, por não ser distante do porto de Santos e estar junto à estrada de ferro, fornecer a todo o Brasil um estrume artificial que faria não somente dobrar a produção das plantações já existentes como nos habilitaria a utilizarmos com grande vantagem as terras gastas e inferiores, pondo-nos em posição de produzir gêneros alimentícios, que hoje nos vem em tão grande escala do estrangeiro e cujo valor monta em muito mais de cem mil contos. (QUEIROZ, 1895, p. 126).
\end{abstract}

Alertava Vicente Queiroz que os paulistas poderiam produzir o seu próprio insumo, ou ao menos, uma de suas bases principais, o fosfato de cal, a partir da exploração da chamada “jazida de Ipanema”, economizando na importação daquele produto, facilitando o acesso e tornando-o mais barato ao maior número de lavradores possível, visto o barateamento que uma produção nacional, ou paulista, poderia suscitar. Em sua opinião, o governo deveria, o quanto antes, arrendar, explorar ou vender aquelas “ricas jazidas” e em caso algum deveria mantê-la inexplorada por mais tempo,

“[...] pois hão de contribuir forçosamente para debelar a nossa crise financeira (lembre-se da crise cafeeira e monetária debelada em 1895-96), nos poupando a vergonha de ser o Brasil o único país novo que importa em tão larga escala gênero alimentício; assim muito melhorariam as nossas finanças, o que viria também 
A Moderna Agricultura no final do século XIX em São Paulo:

algumas propostas.

auxiliar a consolidar nossas instituições, porque com boa finança é muito mais fácil fazer boa política”(QUEIROZ, 1895, p. 125-126).

Essa preocupação de Queiroz era recorrente aos autores da Revista Agrícola: como poderia um país como o Brasil, um Estado como o de São Paulo, farto em terras férteis ou passíveis de exploração agrícola, não produzir alimentos para o seu próprio sustento. De fato, o Brasil, e não apenas São Paulo, importava diversos gêneros alimentícios como arroz, trigo e outros, e isso durante muito tempo (SALLUM JUNIOR, 1982) ${ }^{19}$. Por exemplo, em 1903, apenas em São Paulo, a exportação do que chamou o Secretário de Agricultura de "artigos destinados à alimentação e forragens”, alguns deles que poderiam ser produzidos no próprio Estado, custaram com importação 33.295:799\$ (SÃO PAULO, 1905, p. 79).

Não obstante, havia também críticas ou observações quanto ao uso sem métodos, ou poucas técnicas e conhecimentos, quanto à compra, manipulação, quantidades, e outros, dos adubos químicos, como advertiam alguns autores pesquisados. Segundo um artigo na Revista Agrícola, as vantagens do uso da cal na agricultura eram conhecidas há muito tempo, "o que não quer dizer, todavia que a sua aplicação se fizesse, tanto quanto o estão reclamando os terrenos faltos daquele elemento de vida.” (G.P., 1897, p. 179). O autor advertia, ainda, que direta ou indiretamente, a cal “concorre” para algumas das funções mais importantes da fisiologia vegetal. "É não só alimento, mas converte em alimentação muitas das matérias, que existem inertes no solo” (G.P., 1897, p. 179). Para G.P. (1897). Estaria provado pela ciência, naquele momento, que os vegetais, “que se empregam na arte culinária, e igualmente as frutas, não tem tão boas qualidades, tão delicado sabor, se o terreno onde foram produzidas se achar pobre de cal”. Devido a isso, segundo ele:

Os lavradores fazem em geral grande despesa com adubos e não colhem resultado correspondente, por que não sabem fazer a devida escolha e o conveniente emprego dos adubos, onde é indispensável que entrem certas matérias, como a potassa $^{20}$, a soda ${ }^{21}$, a cal, a alumina ${ }^{22}$, etc.

Em razão do nome, há quem pense que a cal aquece o que está frio e que divide o que está muito apertado ou compacto.

Isto não passa, todavia de um preconceito. (G.P., 1897, p. 179-180) ${ }^{23}$.

O autor salientou aos leitores do periódico que a cal convinha ser aplicada em todos os terrenos em cuja composição houvesse carência daquele produto, fossem eles terrenos de argila compacta ou de areia silicosa, o xisto ou o granito. A cal deveria "fazer parte do sustento dos cereais, das plantas industriais e dos legumes”. Não funcionava, a seu ver, somente como elemento 
nutritivo, "mas também como substância para decompor e ainda como substância própria para impedir o efeito dos ácidos e destruir os insetos nocivos.” (G.P., 1897, p. 180).

Desta maneira, quando a cal fosse destinada a terrenos com abundância de detritos vegetais naturais e oriundos da queimada das florestas, ou colocados pelo próprio homem como restos de outras plantações, portanto, adubo natural, conviria empregar a cal “viva ou cáustica”, quando possível, e na razão de 100 a 129 hectolitros $^{24}$ por hectare ${ }^{25}$, e quando fosse destilada (ou dissolvida) serviria "somente a corrigir, a neutralizar a acidez de um terreno ou a enriquecê-los de elementos calcários, ou ainda quando se deseja misturá-la com os estercos, é melhor empregá-la extinta (neutra).” (G.P., 1897, p. 180). Este seria, a seu ver, o melhor modo de corrigir um terreno ácido utilizando a cal para adubação.

A despeito do uso da terra para a agricultura, o fazendeiro e industrial, Luiz de Queiroz era enfático e crítico quanto à prática das queimadas das florestas para aberturas de áreas. Para o autor, “destruir soberbas matas de terras ubérrimas, que vão ser entregues para sempre à cultura, não é grande mal e mesmo não se poderia recriminar contra esta prática se toda a madeira de lei fosse aproveitada.” (QUEIROZ, 1895, p. 112). O autor era contra o uso indiscriminado da derrubada e queimada, do pouco aproveitamento do solo durante as décadas e de suas madeiras que poderiam ser utilizadas para diferentes fins, visto que a exploração do solo praticada no Brasil, sem reposição alguma dos nutrientes ao solo, onde as plantações não eram feitas acompanhando o desnível dos terrenos (curvas de nível), o que um historiador denominou de "verdadeiro processo de bombeamento dos recursos naturais do solo, agricultura extrativa”. (PRADO JR., 1999, p. 136).

Segundo observou Queiroz, na crítica sobre as práticas agrícolas encetadas historicamente:

[...] destruir matas e capoeiras só para tirar duas ou três colheitas, atear fogo em quase um distrito inteiro, para fazer verde (pasto) a algumas cabeças de gado, queimar imensos campos e matas pela locomotiva de estrada de ferro mal dirigida, ou arrasar florestas de íngremes morros, de profundas barrocas de nascentes d’água ou de beira-rio, ou inutilizar as matas junto a centros populosos só para aproveitálas com carvão ou lenha, é simplesmente procedimento de bugres ${ }^{26}$ ou de vândalos $^{27}$ e o governo ou mesmo as Câmaras Municipais deveriam com leis as mais severas pôr um paradeiro a tão insensato, quão imprudente procedimento. (QUEIROZ, 1895, p. 112).

Queiroz advertia, ainda, que devido às queimadas e ao abandono do solo nu com a destruição exagerada das florestas, o clima do país estava se modificando completamente: “as estações tornam-se irregulares, as chuvas ora vem cedo, ora tarde, ou são escassas ou são copiosas demais, os rios tornam-se caudalosos”, devido à lavagem e carregamento da camada superficial dos terrenos e a lixiviação, “e há fortes inundações ou então secam quase completamente, a ponto de não darem água para fazer trabalhar a mais insignificante máquina”; os ventos estavam sempre 
A Moderna Agricultura no final do século XIX em São Paulo:

algumas propostas.

emprenhados de "forte camada de pó, o calor, torna-se abrasador; tudo isso contribui para o mal estar dos habitantes e também para a irregularidade da produção, esterilizando o país pouco a pouco”. (QUEIROZ, 1895, p. 112). ${ }^{28}$ No entanto, sabia o viajado industrial que:

[...] se hoje os países os mais adiantados da Europa tem obtido maior produção, não é só devido a sua sabia agronomia, mas a sensata conservação que eles tem sabido dar à suas florestas aumentando-as diariamente e apoiados por sabias leis que são fielmente cumpridas; isto tem também contribuído poderosamente para estabelecer um clima igual, havendo completa uniformidade da mudanças das estações, aumentando sempre sua produção, até não lhe faltando nem lenha, nem madeira que é obtida por preço inferior ao que pagamos nós, o que não deixa de muito contribuir para o seu bem estar. (QUEIROZ, 1895, p. 112).

Portanto, os lavradores brasileiros deveriam cuidar melhor dos seus terrenos e lavouras, "tratar de não destruir tanto as nossas matas e fazer novas florestas em terras inúteis à lavoura e que para o futuro serão de grande interesse pecuniário e verdadeira e sólida herança a família” (QUEIROZ, 1895, p. 112). O autor lembrava, também, de como as essências florestais de crescimento rápido e de excelente madeira (como o cedro, o pinheiro, o guarantã e muitas outras) e as estrangeiras (os eucaliptos, as coníferas, os carvalhos), poderiam fornecer, em alguns anos, material para a construção civil em geral, entre dezenas de outros fins comerciais, desejando ver o desenvolvimento da silvicultura comercial entre os paulistas (QUEIROZ, 1895).

Enfim, Queiroz acrescentava que para a cultura dessas árvores "há despesas só nos primeiros 4 a 5 anos, porque depois a sua conservação poucos gastos ocasiona”; estava convencido de que cada árvore poderia gerar uma renda de um a dois mil réis de madeira por ano. Somando-se a isso estava "a vantagem destas terras muito aumentarem de valor, porque iriam pouco a pouco recuperando as suas forças produtivas.” (QUEIROZ, 1895, p. 112).

\section{Conclusões}

Diante do exposto, da leitura e análise dos artigos da Revista Agrícola paulista, foi possível visualizar o desejo de dezenas de homens, intelectuais, agrônomos, divulgadores entusiastas, políticos e grandes fazendeiros na busca da modernização e melhoramento da produção agrícola (HENRIQUES, 2010). Conquanto se buscasse uma produção mais barata, na economia de força de trabalho, maior rendimento das lavouras, algumas propostas de modernização da agricultura em substituição às técnicas até então praticadas no Brasil, e em São Paulo especialmente falando, carecem de pesquisas e análises pormenorizadas por parte dos historiadores. 
Pesquisas recentes sobre o planejamento territorial moderno em São Paulo destacam que o governo paulista, grandes fazendeiros, agrônomos e intelectuais do período, deram especial atenção para a questão da ocupação e da exploração econômica dos espaços disponíveis do território do estado (OLIVEIRA, 1997). Neste sentido, as propostas da moderna agricultura alinhavam-se com a questão do planejamento territorial moderno, mas não apenas isso. Os idealizadores da modernização agrícola, incluindo o governo do estado, queriam promover uma verdadeira indústria agropecuária com produtos diversificados - apoiada na produção cafeeira -, para o desenvolvimento do mercado interno e externo.

Neste sentido, as propostas de modernização agrícola giravam em torno de diferentes assuntos, mas sempre interligados, como: diversificação da agricultura, adubação química e natural, cultura intensiva do solo, mão de obra, povoamento e colonização, instalação de núcleos coloniais dentro dos moldes da moderna agricultura então desejada, instrução agrícola por meio de campos de experiências e demonstração, ensino agrícola para diferentes graus, mecanização da lavoura, o que era chamado na época de Moderna Agricultura ou agricultura científica, racional, em substituição ao que era considerado como agricultura rotineira ou atrasada, praticada deste o início da agricultura no Brasil.

Diversas pesquisas sobre o período cafeeiro paulista deram ênfase que a modernização da agricultura não poderia ser realizada, e não se efetivou por motivos de ordem econômica, que levaram os fazendeiros a continuar com o sistema de explorar a terra e o trabalho (SALLUM JUNIOR, 1982). Contudo, estudar as propostas e as tentativas de modernização agrícola pode trazer contribuições importantes ao conhecimento histórico. As propostas de modernização da agricultura foram idealizadas, tentadas por diversos e grandes agricultores, políticos, cientistas de diferentes matizes, e também pelo governo do estado e suas instituições - e não apenas em São Paulo (ZARTH, 2002).

Diante disso, pode-se vislumbrar, nas centenas de artigos contidos na Revista Agrícola, bem como em diversos manuais agrícolas do final do século XIX e século XX adentro, não apenas a feição comercial, econômica e utilitária daquelas propostas, mas também o surgimento de uma consciência particular e, como não, também pública dos recursos naturais e a conservação ou 
A Moderna Agricultura no final do século XIX em São Paulo:

algumas propostas.

ampliação do seu uso no tempo e no espaço pelos homens. A busca da Moderna Agricultura que se desenvolveu durante os séculos XIX e XX.

\section{Notas:}

${ }^{1}$ Embora a pesquisa de mestrado procure ler e analisar uma ampla gama de manuais, memórias agrícolas, bem como centenas de artigos na Revista Agrícola, no momento, a preocupação será concentrada na leitura de apenas alguns artigos e autores.

${ }^{2}$ Revista Agrícola. Órgão da Sociedade Pastoril e Agrícola. São Paulo, 1895. Este periódico possuía publicação mensal, circulando em vários Estados brasileiros, mas principalmente em São Paulo, onde possuía sua maior acolhida em assinaturas. A revista seguiu publicação entre os anos de 1895 a 1907 somando 149 números com uma média de 35 a 45 páginas cada edição, sendo substituída pela revista Fazendeiro, revista mensal de agricultura, indústria, comércio, dedicada especialmente aos interesses da lavoura cafeeira. São Paulo: Tip. Brazil Rothchild \& Cia, em 1908. A Revista Agrícola passou por diversas reformulações estruturais durante o curso dos anos, modificando-se também em relação a seus proprietários, e no período de 1895 e 1896 seu proprietário era a Sociedade Pastoril e Agrícola tendo como diretor o fazendeiro José Leite da Costa Sobrinho, e redatores Carlos Botelho, Luiz Pereira Barreto e J. N. Domingos Jaguaribe. De 1901 a 1907 seu diretor foi Fernando Werneck, fazendeiro em São Paulo, tendo como redatores, Carlos Botelho, Luiz Pereira Barreto e Santos Werneck, todos fazendeiros em São Paulo. Neste período o periódico era de propriedade da Sociedade Paulista de Agricultura, Comércio e Indústria.

${ }^{3}$ A expressão é de Costa e Schwarcz (2000).

${ }^{4}$ Sobre o trabalho nas fazendas, repressão, violência, miséria aos trabalhadores rurais.

${ }_{6}^{5}$ Revista Agrícola.

${ }^{6}$ Para Robert de Moraes, o uso do conceito de recurso natural aparece intrínseco a uma dada sociedade, que tem a função de discriminar alguns elementos da natureza para que pudessem ser utilizados em processos produtivos e gerais. Assim, a elaboração e uso deste conceito, no século XIX, só pode ser entendido como parte dos mecanismos de produção e reprodução do capitalismo brasileiro. (MORAES, 1994, p. 101-103). No caso de como os recursos naturais foram explorados e concebidos no Brasil em diferentes momentos, ver Sevcenko (1996).

${ }^{7}$ É o que sugere Iraci Salles (1986) com o advento do PRP, em São Paulo.

${ }^{8}$ A expressão em destaque é encontrada neste e em diversos autores.

${ }^{9}$ Capanema era especialista em mineralogia. Participou da Sociedade Velosiana de Ciências Naturais, onde colaborava na comissão de botânica. Ajudou a fundar a Sociedade Palestra Científica do Rio de Janeiro. Participou da Comissão Científica do Instituto Histórico e Geográfico do Brasil, criada em 1856, onde foi diretor da Seção Geológica e Mineralógica. Foi diretor da Fábrica de Ferro de Ipanema, em Iperó, hoje Sorocaba, revitalizado-a. Ao que parece, desenvolveu também um formicida contra a formiga saúva, considerada na época um dos piores flagelos da agricultura, bem como realizava diversas experiências na área agrícola.

${ }^{10}$ Camada de folhas, galhos, etc., de mistura com terra, que cobre o solo da mata. Ou designação comum às pequenas raízes que surgem à flor da terra. É a matéria orgânica depositada no solo por séculos pela floresta. Também pode ser considerada como húmus.

${ }^{11}$ Conhecida como samambaia, e a G. brasiliana, nativa em quase todo o Brasil, vulgarmente chamada samambaia-domato-virgem. Algumas espécies de samambaias eram encontradas em terrenos desgastados e pouco férteis depois de sucessivos usos e consequente abandono.

${ }^{12}$ Qualquer sal do ácido fosfórico. O fosfato é um importante elemento de nutrição das plantas.

${ }^{13}$ Adubo inorgânico que se obtém tratando fosfato de cálcio pelo ácido sulfúrico concentrado, e que é uma mistura de fosfatos e sulfato de cálcio.

${ }^{14}$ Qualquer sal ou éster derivado do ácido nítrico muito usado na agricultura.

${ }^{15}$ Sulfato é qualquer sal do ácido sulfúrico. Alguns compostos são usados na agricultura.

${ }^{16}$ Pó ou miudezas de carvão. Ou o que se obtinha com o procedimento da varredura dos campos cultivados. Tudo o que se obtinha de resíduos dentro de uma propriedade agrícola: cinzas de queimas diversas, do fogão, do pasto; urinas e excremento de diversos animais, etc., deveriam ser usados para a adubação.

${ }^{17}$ Fundador da Escola Agrícola Prática "Luiz de Queiroz", hoje a conhecida Escola Superior de Agricultura Luiz de Queiroz (ESALQ-USP). Para saber mais sobre essa instituição, ver Perecin (2007).

${ }_{18}$ Que despende com excesso; dissipador, esbanjador. Que dá, distribui, faz ou emprega profusamente e sem dificuldade.

${ }^{19}$ Alguns autores afirmam que a produção para consumo interno (gêneros alimentares) apenas conseguiu suprir a demanda do mercado interno em São Paulo nas décadas de 1920-30. 
${ }^{20}$ O hidróxido de potássio, cloreto de potássio e o nitrato de potássio são compostos utilizados como fertilizantes.

${ }^{21}$ Hidróxido de sódio.

${ }^{22}$ Trióxido de dialumínio.

${ }^{23}$ Sobre o autor, a sigla G.P., provavelmente, deva se tratar de Bernardo Avelino Gavião Peixoto (1829-1912) que escrevia com certa recorrência na Revista Agrícola.

${ }^{24}$ Medida de capacidade, equivalente a 100 litros.

${ }^{25}$ Unidade de medida agrária, equivalente a 100 ares. O are é também uma unidade de medida agrária e equivale a 100 metros quadrados.

${ }^{26}$ Referindo-se a um indivíduo rude, inculto.

${ }^{27}$ Num ato de destruição de uma coisa útil, que deveria ser mais bem aproveitada neste sentido.

${ }^{28}$ A referência feita para "máquinas” corresponde aos aparelhos movidos à força hidráulica existentes em diversas propriedades.

\section{Referências:}

\section{Fontes:}

SÃO PAULO. Secretaria da Agricultura, Comércio e Obras Públicas. Relatório da Agricultura, apresentado ao Dr. Jorge Tibiriçá pelo Dr. Carlos Botelho, Secretário da Agricultura. 1904. São Paulo: Tipografia Brasil de Carlos Gerke. 1905.

Revista Agrícola Órgão da Sociedade Pastoril e Agrícola. São Paulo, 1895.

REVISTA AGRÍCOLA. "Indústria Pastoril - A Indústria Pastoril em São Paulo - Seu Presente e seu Futuro - A Sociedade Pastoril e Agrícola - A ‘Revista Agrícola’”. n. 1 ano I, 1895. p. 1-5.

CAPANEMA, G. S. As Queimadas. Revista Agrícola, ano I, n. 6, 1895. p. 91-93.

G. P. A Cal e a Agricultura. Revista Agrícola, ano III, n. 24, 1897. p. 179-180.

QUEIROZ, L. V. de S. “Fosfato de Cal.” Revista Agrícola, ano I, n. 8, 1895, p. 126-127. “Apelo ao Governo e às Câmaras Municipais - Destruição das Matas.” Revista

Agrícola, ano I, n. 7, 1895. p. 112.

\section{Bibliografia:}

COSTA, A. M. da; SCHWARCZ, L. M. 1890-1914: no tempo das certezas. São Paulo: Companhia das Letras, 2000.

DEAN, W. Rio Claro: Um Sistema Brasileiro de Grande Lavoura 1820-1920. Rio de Janeiro: Paz e Terra, 1977.

. A Ferro e Fogo: A História e a Devastação da Mata Atlântica Brasileira. São Paulo: Cia. das Letras, 1996.

FIGUEIRÔA, S. F. de M. Ciência e tecnologia no Brasil Imperial - Guilherme Schuch, Barão de Capanema (1824-1908). Varia História. v. 21, n 34, p. 437-455, 2005. 
FREITAS FILHO, A. P. Tecnologia e escravidão no Brasil: aspectos da modernização agrícola nas Exposições Nacionais da segunda metade do século XIX (1861-1881). Revista Brasileira de História, v.11 (22), p.71-92, mar-abr. 1991.

HENRIQUES, A. M. A Cultura Rotineira e a Lavoura Racional: proposições na Revista Agrícola (São Paulo, 1895-1907). 2010. Dissertação (Mestrado em História) FCL-UNESP-Assis, 2010.

HOBSBAWM, E. J. Era dos Extremos: o breve século XX: 1914-1991. São Paulo: Companhia das Letras, 1995.

A Era do Capital. Rio de Janeiro: Paz e Terra, 1975.

HOLANDA, S. B. de. Raízes do Brasil. São Paulo: Companhia das Letras, 1995.

LEMOS, C. Alvenaria Burguesa. São Paulo: Nobel, 1989.

LOVE, J. L. A Locomotiva: São Paulo na federação brasileira 1889-1937. Trad. Vera Alice Cardoso Silva. Rio de Janeiro: Paz e Terra, 1982.

LUCA, T. R. de. A história dos, nos e por meio dos periódicos. In: PINSKY, C. B. (Org.). Fontes Históricas. São Paulo: Contexto, 2005. p. 111-153.

MATOS, O. N. de. Café e Ferrovias: A evolução ferroviária de São Paulo e o desenvolvimento da cultura cafeeira. 4 ed. Campinas: Pontes, 1990.

MARTINS, A. L. Revistas em Revista: imprensa e práticas culturais em tempos de República, São Paulo (1890-1922). São Paulo: Edusp, 2001.

GRAZIANO NETO, F. Questão Agrária e Ecológica: Crítica da Moderna Agricultura. São Paulo: Brasiliense, 1982.

PERECIN, M. T. G. Os Passos do Saber: a Escola Agrícola Prática Luiz de Queiroz. São Paulo: Editora da Universidade de São Paulo, 2007.

PRADO JR., C. Formação do Brasil Contemporâneo. 23. ed. São Paulo: Brasiliense, 1999.

SALLES, I. G. Trabalho, Progresso e a Sociedade Civilizada: o Partido Republicano Paulista e a Política de Mão-de-Obra (1870-1889). São Paulo: Hucitec, 1986.

SALLUM JR., B. Capitalismo e Cafeicultura: Oeste Paulista - 1888-1930. São Paulo: Duas Cidades, 1982.

SEVCENKO, N. Literatura como Missão: tensões sociais e criação cultural na Primeira República. 2. ed. São Paulo: Companhia das Letras, 2003.

30, p. 108-119, 1996.

O Front Brasileiro na Guerra Verde: vegetais, colonialismo e cultura. Revista USP, n.

STOLKE, V. Cafeicultura: Homens, Mulheres e Capital (1850-1980). São Paulo: Brasiliense, 1986. 
WORSTER, D. Transformações da Terra: Para uma Perspectiva Agroecológica na História. Ambiente \& Sociedade. v.5, n.2, ago./dez. 2002 - v.6 n.1, jan./jul. 2003.

Recebido em 16/06/2011

Aprovado em 19/10/2011. 